\title{
Rethinking Communication and Crowdsourced Technology: Mediating Role of Mobile-Learning Tie to Broadband
}

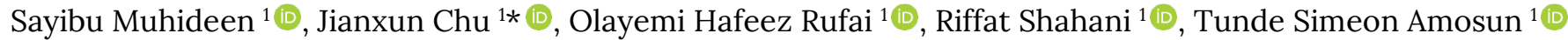

${ }^{1}$ University of Science and Technology of China, Anhui-Hefei, CHINA

*Corresponding Author: chujx@ustc.edu.cn

Citation: Muhideen, S., Chu, J., Rufai, O. H., Shahani, R., \& Amosun, T. S. (2021). Rethinking Communication and Crowdsourced Technology: Mediating Role of Mobile-Learning Tie to Broadband. European Journal of Interactive Multimedia and Education, 2(1), e02106. https://doi.org/10.30935/ejimed/9703

\begin{abstract}
The proliferation of online crowdsourcing information via mobile technology intervention achieved progressive learning in recent times. The study seeks the mobility of crowds using internet-contents as crowdsourcing knowledge phenomenon in community-learning task actualization. Bandura's Social Learning Theory (SLT) and TPB induced and investigated 361 respondents among international students using IBM Amos v. 25 for the analysis. Results found exogenous variables were positively significant, whiles broadband moderation on mobile learning behavior run-up. Mobile learning mediation magnifies the behavior actualization effectiveness. Significantly, crowdsource at the individual level colored internet-content via mobile learning technology collaborated communication problem-solving tasks. Mobility of learning makes a mountain of molehills in knowledge sourcing, communication community-centered performance.
\end{abstract}

Keywords: technology, mobile learning, crowdsourcing (SC), broadband, innovative communication

Received: 18 Aug. 2020 Accepted: 22 Nov. 2020

\section{INTRODUCTION}

Technology progress on 'crowd-learning' source emanates on communication through innovative mobile-learning constellation in society (Cortez, 2020). Crowdsource technology is an interactive communication process digital knowledge-sourcing, influenced by internet content in a dispersed crowd (learners). Epi Ludvik (2018) crowdsource modeled around virtual communication in a digital society, environment all done under the power of crowds on webcontents (Peng, Liang, \& Zhu, 2019). Communication is a social process influence by repository sites, content meaningful to a crowd of learners (Wang, Ding, \& Yu, 2019). Buecheler et al. (2010) classified Wikipedia as crowdsource whiles Huberman et al. (2009) also viewed YouTube typical example of crowdsourcing open-innovation. Mobile learning communication is a continuous performance collaborative for effective broadband in higher learning setting (Halder, Halder, \& Guha, 2015), pivotal human-centric nodes connect learners in the social setting (Smirnov, Easterday, \& Gerber, 2018). The study seeks to unearth the mobility communication among learners knowledge-sourced via internet-content social collective task performance empowered by the systemic broadband pool (Paulin \& Haythornthwaite, 2016).

The application of mobile sources in the educational reign reinforces the mobile users network-connected by a unique form of centrality index: Google, Baidu, bing, Wikipedia for information (Swanlund \& Schuurman, 2016). The current dispensation of smartphone user demographics surpasses a 3billion forecasted growth rate of 700 million in the future (Statista, 2019). The daily time spent on sourcing information from mobile handheld devices has enhanced continuous education at any time, estimated more than 4 hours a day for learning tendencies. The efficiency of mobile broad-bandwidth justifies the numerous behaviors of user effectiveness (Petrovčič, Slavec, \& Dolničar, 2018). Again, the self-learner tendency over the technology makes a cogent connection to a broadband mobile-device for information surfing, insightfully accessible in a larger group (crowds). Learners view that the world web-based knowledge simplifies learning mobility accessible via the internet-content (Çakar Mengü \& Mengü, 2017). The era of science and technology advocacy of internet information systems using mobile communication is farfetched. In the academic learning domain, the technology synergy has enabled self-learner motivation and retention, in a group or individually, in resolving tasks interactive settings (Gregori, Zhang, et al., 2018).

The study purpose proposed two objectives; firstly, socio-Integra mobile technology crowdsource-learner usefulness as collaborative and effective continuous education effectiveness through broadband efficacy. Integrated social-community learning concepts, cognitively processes online content communication in the absence of instructions, motor reproduction, or reinforcement. The second objective is to explore broadband moderation and mobile learning behavioral mediation over performance actualization in education. Mobile behavior as an intervention process enables retention, motivation, and 
performance actualization. There is a scanty body of knowledge on the individual crowdsourcing technology as internet-content enlightenment. Specifically, broadband internet-coordinates mobile learning will ascertain the relationship accomplishment of individual mobile collaborative learning in the community (ambient selflearning).

RQ: To what extent can crowdsource technology communication efficiency augment online learning at personal knowledge sourcing?

Social Learning Theory (SLT) and Theory of Planned Behavior (TPB)

This research on mobile communication centers on the psychological perspective of technology. We focus on knowledgecentered and community-centered communication technology connecting to learners' perceptions, expectations, and attitudes towards the digital age (Cumiskey \& Ling, 2015; Keenan, Presti, \& Dillenburger, 2019). Using combined theories from Albert Bandura's (1997, 2001), Social Learning Theory (SLT) postulates a social learning experience (behaviorism) to the scientific attitude of technology, the cognitive process juste milieu mobile learning. Theory of Planned Behavior (TPB) Ajzen, iSALT Team $(1993,2014)$, and Sharples, Taylor et al, (2005), Mobile Learning Theory. Among these theories, we adapted (MLB-mobile learning theory), (PSLU, PCS, -theory of planned behavior) and (Attitude, BIP- social learning theory) with added broadband. Perceived usefulness by virtue of TPB, modified as perceived self-learner usefulness (PSLU) to meet the adequacy of mobile behavior of learner's vis-a-vis internet broad-bandwidth efficiency. PSLU is the learner's belief that using the mobile device will enhance good academic performance (knowledge-centered) (Davis, Bagozzi, \& Warshaw, 1989). Behaviorism has a relationship with the intention of a user's performance to influence community-centered learning (Yang, Lin, \& Liu, 2017). Bandura's book of reciprocal interaction, factors of influence; behavioral; environment; and personal inter-connected to mobile learning vicarious psychology affecting trends of crowdsourcing technology setting (Riley et al., 2019; Schunk \& DiBenedetto, 2020).

\section{Research Hypotheses and Relevance of Literature Review}

Generally, social psychological theories of human behavior will subjectively produce a certain outcome of performance in mobile communication technology. Bandura (1991), underscore outcome expectancy in the expectancy-value model, linking Attitude, and Behavior expectation either learner or user-centered. The theory of plan behavior's deductive evaluation of an individual's behavior is congruent to perceived benefits to technology collaboration (Doargajudhur \& Dell, 2018). Useful technology is a situation influenced by a network of crowd communities. The theory implies that the technology of mobile communication useful to learners' selflearning online is adequate, where the internet signifies crowd information sourcing, influenced by technology (Seidel, Langner, \& Sims, 2017; Toyama, 2018). These attitudes correlate to behavior intention in performing the task in use of the mobile device to accomplished knowledge-centered.

Conceptually, learning is personal, so the use of mobile communication in social learning theory (Bandura, 1991; Sharples et al., 2005). Mobile technology offers personalized, just as learning is situated and collaborative community-centered. The perceived self-learner usefulness (PSLU) with personal smart mobile communication is a network to knowledge sharing (Alqahtani \& Mohammad, 2015). Mobile communication technology is an innovative pedagogy in the era of self-learning regulated activities, enables crowd-learning no matter the location (Campbell, Detres, \& Lucio, 2019). The advent of COVID19 set out many situational online distance courses, of which mobile technology communication engineers most of the programs across all learning centers globally (Lin et al., 2019). This is because smart-phones are common than computers for self-learning.

The pool of information from the internet tasked a group of individuals, this serves online learning mechanisms for problemsolving (Gün, Demir, \& Pak, 2019; Su, Sui, \& Zhang, 2018). Therefore, formal repository internet sites, social media interaction, central network sharing knowledge are crowdsourced technology (Rodríguez et al., 2017). A crowd community of learners, network communicated to others through the mobile facilitated knowledge sharing in task performance (Sheng \& Hartono, 2015). Mozzala and Distefano (2010) and Crittenden et al. (2018) argued that a way of outsourcing to crowd task is a pool of information sharing, collaboratively aim to harness a wide variety of skills and learn from experts efficiently in a network. Boudrean and Lakhani (2015) concludes the online crowdsource via sharing or receiving information communication is solution enough for learners' exchange of ideas and rejuvenate direct personal communication.

H1: Attitude has a positive and significant effect on behavior performance.

H2: Perceived Self-Learner Usefulness has a positive and significant effect on behavior intention.

H3: Perceived Crowdsource (CS) is a positive/negative homogeneity to behavior intention.

Mobile Learning behavior (MLB) is a social process, lifelong learning, occurred either formal or informal mediated by technology of users' time. Empirically, teens are more with mobile activities in their daily lives than adults, this is because they are born in the internet era, they turn to abuse the information communication and technology. As of 2015, age ranges from (13-14years) of $83 \%$, and $93 \%$ of (15-17years) have access to smartphones than tablets (Alenezi \& Salem, 2017). According to Hossain et al. (2019), the psychology behind mobile learning behavior in relationship to intention acceptance and actual performance is based on policy. Mobile learning behaviors for knowledge sharing certainly perceived mobility and social support system rationale for user intention in performance. The Internet enables mobile communication to speed up information wirelessly network communication (Eze, Sadiku, \& Musa, 2018). Constraints in the mobility of knowledge sharing, poor quality interruptions, seamless interruptions handover, expensive data the least to discuss the better. The hypothesis will ascertain the potential of internet broadband connectivity for effective mobile learning outcomes.

H4: Mobile-Learning behavior mediates tie-in Attitude and Behavior performance.

H5: Mobile Learning behavior mediates tie-in PSLU and behavior performance.

H6: Mobile-Learning behavior mediates tie-in PCS and behavior intention performance.

H7: Mobile Learning behavior has positive and significant effects on behavior intention performance. 


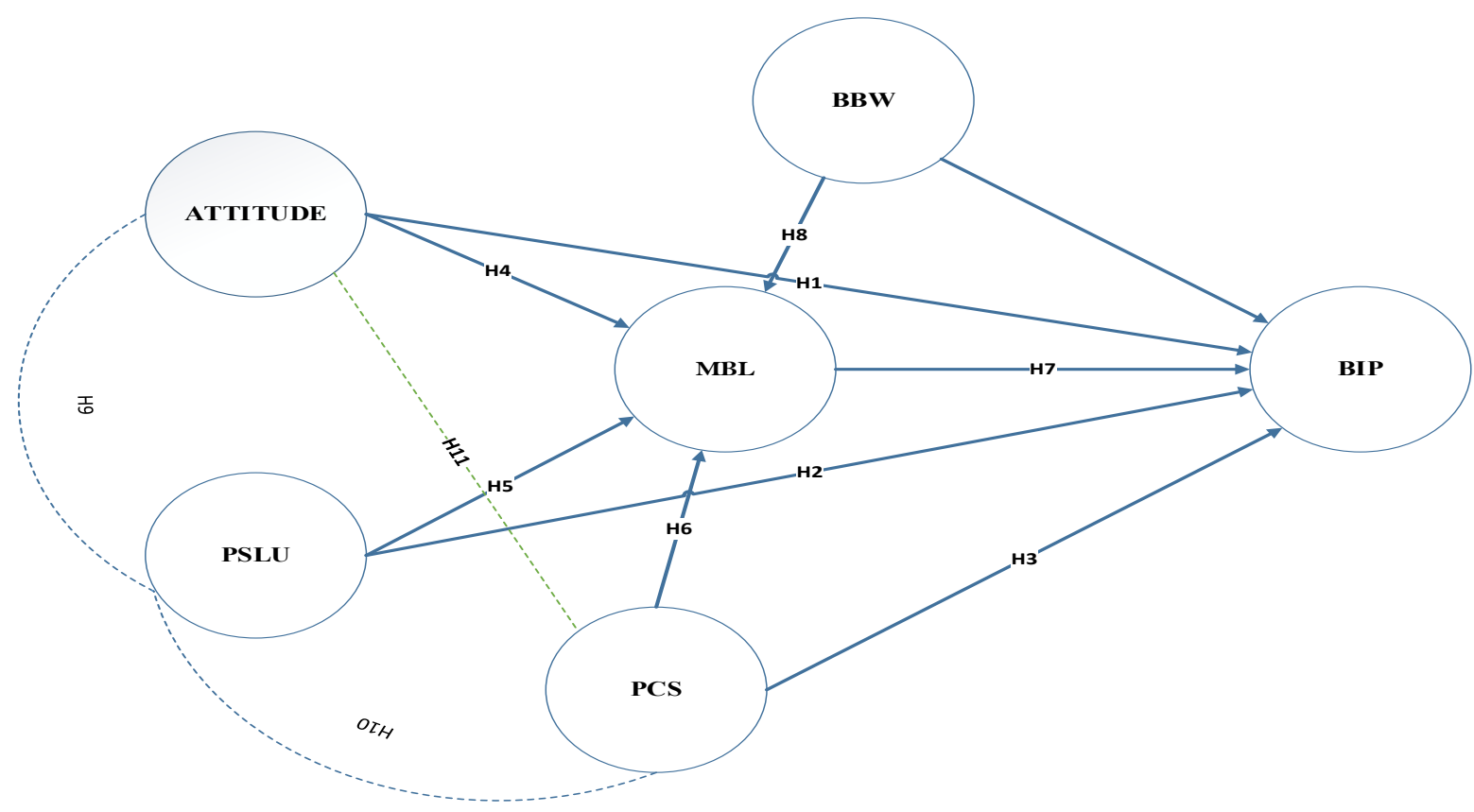

Note: PSLU $=$ Perceived Self-Learner Usefulness, $\mathrm{PCS}=$ Perceived Crowdsource, BBW= Broad Bandwidth, MLB= Mobile Learning Behavior, BIP= Behavior Intention Performance

Figure 1. Conceptual Framework

H8: Broadband moderates on mobile learning behavior.

H9: Attitude has a relationship with perceived self-learner usefulness.

H10: Perceived self-learner usefulness has a relationship with perceived crowdsourcing.

H11: Attitude has a direct relationship with perceived crowdsourcing.

The behavior intention (BI) is to actualized technology as dependent constructs. The motivational aspects of how the intention to perform the behavior is likely that behavior will be performed (Bervell \& Umar, 2018). The openness and readiness of the individual to perform an intended behavior could be immediate or otherwise (Ayvazo, 2015). Ajzen (1991) explains behavior as a function of compatible intention and perception of behavioral control to expect mobile behavior significantly affects behavior intention. In this instance, the intention is felt when the perceived behavior control is stronger in model performance. Learners' instinct motivation is a conscious plan or decision to use mobile communication technology, though scholars differ in philosophy and/or psychology perspective in considering social behaviors, social psychology, and social cohesion (Pagani, 2014).

\section{Research Methodology and Data Collection}

The study quantitatively by the induction method of structural equation model formulated as Figure 1, the various relationships and structural model. The survey encompassed questionnaires using online KwikSurvey sent to respondents, mostly international students in China via emails, WeChat, and WhatsApp responses. Using the random sampling technique for the distributed 450 questions online retrieved 361 represented $80.2 \%$ of the respondent's rate, no recompense is given to avoid biases. The study resulted in more male responses than females; $65.4 \%$ and $34.6 \%$, respectively, from Table 1 .
The young internet user population has affirmed this study indicating age range (19-22years) overweigh the rest with $32 \%$ followed range (2325 years) with 23\% and 27\% from Table 1 all control variables are summarized. The general empirical study indicated $93 \%$ of social media users are teens within the age category of (18-29 years) presumable mobile learning de facto (Yang \& Lin, 2019).

In addition, the constructs were six with thirty items adapted from previous scholarly measurements, that met test reliability results. Some modifications were done to the questions to accurately suit this study of mobile crowdsourcing technology. In each construct measured with five items using the 5 point Likert score from strongly agree to strongly disagree (1-5), respectively (Beglar \& Nemoto, 2014). The questions were skewed in negatives and positives to blurred away reliability problems in analysis (Sharma \& Misra, 2017). Research ethics adhered to by assuring respondents of the confidentiality of data and purposely for academics.

\section{Data and Model Results Analysis}

The second generational approach of SEM (AMOS) for in-depth inter-relationships among latent constructs (Hair, Ringle, \& Sarstedt, 2013). Fundamentally, the structure employs combined quantitative data alongside the correlations and causal effect in the hypotheses of the study. Mathematically, the control variables estimation and Cronbach Alpha (@) from Table 2 with SPSS v.25 verified and confirmed the validity and reliability of constructs (Sánchez-Prieto, OlmosMigueláñez, \& García-Peñalvo, 2016). In Figure 1, first using SPSS to examine the loading higher than 0.5 and fittest to the data (Van der Linden, Klein Entink, \& Fox, 2010). The model test captured measurements and structural models for a satisfactory dimension of validity and reliability (Awang, Afthanorhan, Mohamad, \& Asri, 2016). From Table 2, the CR $\geq 0.6$ satisfied composite reliability benchmark. Firstly, some initial redemptions and refinements were carried out using SPSS for factor loadings; the lower loadings make way for 
Table 1. Demographics of the Study

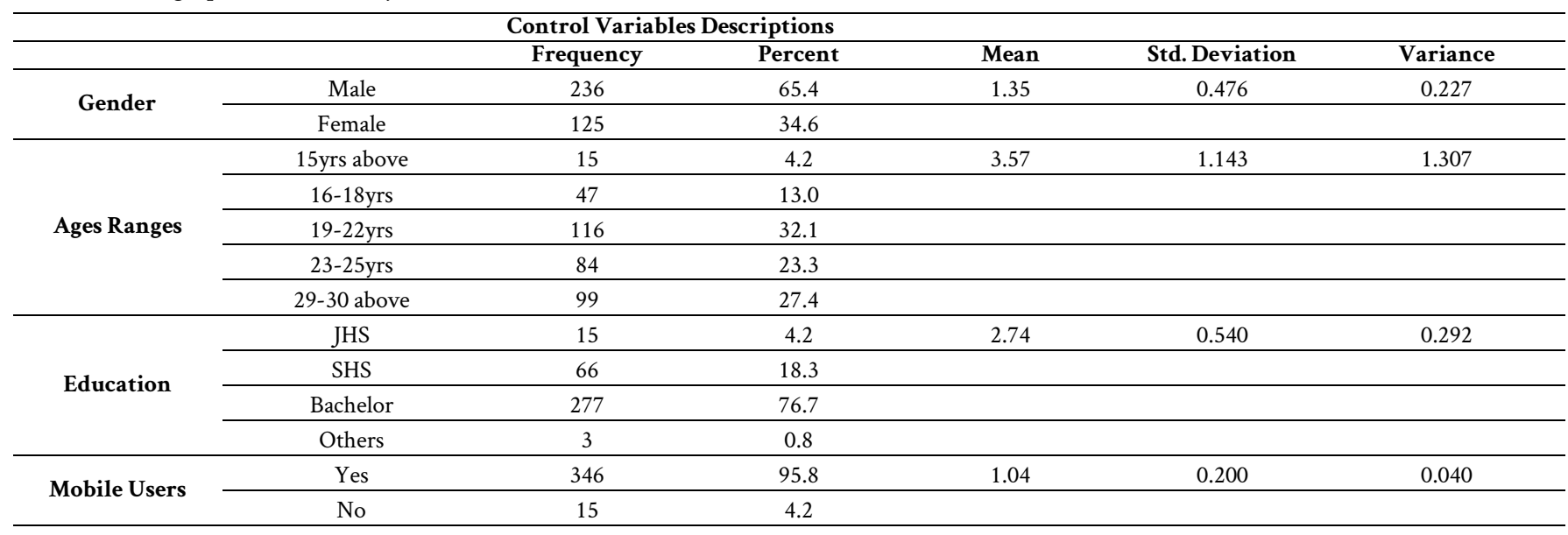

Note: $\mathrm{SD}=$ Standard Deviation

Table 2. Factor loadings of Data response

\begin{tabular}{|c|c|c|c|c|c|c|}
\hline \multicolumn{7}{|c|}{ Factor Loading Analysis Results obtained } \\
\hline Variables & Factor Loadings & SMC & 1-SMC & CR & AVE & $@$ \\
\hline MLB1 & .907 & 0.823 & 0.177 & 0.933 & 0.777 & 0.905 \\
\hline MLB2 & .891 & 0.794 & 0.206 & & & \\
\hline MLB4 & .872 & 0.760 & 0.240 & & & \\
\hline MLB3 & .854 & 0.729 & 0.271 & & & \\
\hline BBW2 & .894 & 0.799 & 0.201 & 0.932 & 0.774 & 0.903 \\
\hline BBW4 & .882 & 0.778 & 0.222 & & & \\
\hline BBW1 & .878 & 0.771 & 0.229 & & & \\
\hline BBW5 & .864 & 0.746 & 0.254 & & & \\
\hline $\mathrm{BI} 2$ & .860 & 0.740 & 0.260 & 0.909 & 0.715 & 0.868 \\
\hline BI4 & .857 & 0.734 & 0.266 & & & \\
\hline BI1 & .841 & 0.707 & 0.293 & & & \\
\hline $\mathrm{BI} 3$ & .824 & 0.679 & 0.321 & & & \\
\hline PSLU5 & .835 & 0.697 & 0.303 & & & \\
\hline PSLU2 & .774 & 0.599 & 0.401 & & & \\
\hline PSLU1 & .743 & 0.552 & 0.448 & & & \\
\hline PCS2 & .930 & 0.865 & 0.135 & 0.945 & 0.851 & 0.913 \\
\hline PCS3 & .929 & 0.863 & 0.137 & & & \\
\hline PCS1 & .909 & 0.826 & 0.174 & & & \\
\hline Att2 & .904 & 0.817 & 0.183 & 0.916 & 0.783 & 0.857 \\
\hline Att1 & .879 & 0.773 & 0.227 & & & \\
\hline Att3 & .872 & 0.760 & 0.240 & & & \\
\hline
\end{tabular}

Note: $\mathrm{CR}=$ composite reliability, AVE = average variance extract, @ = Cronbach Alpha

modifications indices of items in the measurement model. The structural model gave in some deleted items in the output factor loadings, as in Table 2 shows an acceptable threshold 0.7 for the structural equation model procedure. Table 2 indicates the highest factor loading is 0.930 , and the lowest is 0.743 . Secondly, the principal component analysis was carried out to show results higher than the threshold of 0.7 as in Table 2 (Fornell \& Larcker, 2016; Hair et al., 2014). A further test was done for convergent validity using the average variance extract (AVE) and composite reliability measures as in Tables 2 and 3. Also, the AVE value higher than 0.5 sufficiently satisfies the benchmark of convergent validity for the items (Furr \& Bacharach, 2014). From Table 3, results analysis of AVE justifies the measurement model of latent constructs validates the correlations of values higher than discrepancy. It, therefore, goes further to juxtaposed the AVE square root value higher than correlations among the constructs, sufficient argument of convergent validity from Table 3 .

\section{Measuremen ts and Structural Model Evaluation}

Among the evaluation Fitness Indexes in the structural equation model, no agreeable scholarly indexes; however, Hair et al. $(1995,2010)$, recommended the least one fitness index of model fit. Generally, three categories of model fit, namely, absolute fit, incremental fit, and parsimonious fit. This study will report all the three with their respective informative model fit, level of each acceptance in Table 4, even though literature can vary in terms of cut-off thresholds by researchers considering the perspective of the study.

Table 4 shows categories of model fit and their measurements considered Discrepancy Chi-Square, Root Mean Square of Error Approximation (RMSEA), Good of Fit Index (GFI), Adjusted Goodness 
Table 3. Fornell-Larcker Discriminant Validity Results

\begin{tabular}{|c|c|c|c|c|c|c|c|}
\hline Variables & Means(SD) & BI & ATT & PSLU & PCS & BBW & MLB \\
\hline BI & $3.70(1.26)$ & 0.720 & & & & & \\
\hline ATT & $4.08(1.09)$ & $.725^{* *}$ & 0.780 & & & & \\
\hline PSLU & $1.92(1.20)$ & $.702^{* *}$ & $.690^{* *}$ & 0.702 & & & \\
\hline PCS & $3.91(130)$ & $.564^{* *}$ & $.596^{* * *}$ & $.614^{* *}$ & 0.796 & & \\
\hline BBW & $3.91(1.21)$ & $.529^{* * *}$ & $.563^{* * *}$ & $.556^{* * *}$ & $.681^{* * *}$ & 0.799 & \\
\hline MLB & $4.12(1.16)$ & $.518^{* *}$ & $.502^{* * *}$ & $.489^{* * *}$ & $.543^{* * *}$ & $.635^{* *}$ & 0.725 \\
\hline
\end{tabular}

Note: BI = behavior intention, ATT $=$ attitude, PSLU = perceived self-learner usefulness, PCS = perceived crowdsource, BBW $=$ internet broad bandwidth, MLB = mobile learning behavior, $\mathrm{SD}=$ standard deviation. Correlation sign is ${ }^{* *} \mathrm{P}<0.005$

Table 4. The goodness of Fit Indexes Measurement (SEM)

\begin{tabular}{|c|c|c|c|c|}
\hline \multirow{2}{*}{ Categories } & \multirow{2}{*}{ Indexes } & \multirow{2}{*}{ Threshold } & \multicolumn{2}{|c|}{ Results } \\
\hline & & & Measurements model & Structural model \\
\hline \multirow{3}{*}{ Absolute fit } & Chi-Square & $\mathrm{P}>0.05$ & 0.005 & 0.005 \\
\hline & RMSEA & $>0.08$ & 0.052 & 0.057 \\
\hline & GFI & $>0.90$ & 0.907 & 0.977 \\
\hline \multirow{5}{*}{ Incremental fit } & AGFI & $>0.90$ & 0.883 & 0.903 \\
\hline & CFI & $>0.90$ & 0.956 & 0.978 \\
\hline & TLI & $>0.90$ & 0.957 & 0.953 \\
\hline & NFI & $>0.90$ & 0.923 & 0.948 \\
\hline & IFI & $>0.90$ & 0.956 & 0.968 \\
\hline Parsimonious fit & Chisp/df & $<3.0$ & 1.992 & 2.621 \\
\hline
\end{tabular}

Note: RMSEA = root man square of error approximation, GFI= good of fit index, AGFI= adjusted goodness of fit index, CFI $=$ comparative fit index, TLI= tuckerlewis index, $\mathrm{NFI}=$ normed fit index, Chsq/df= Chi-square/degree of freedom, ${ }^{*} \mathrm{P}<0.01,{ }^{* * \mathrm{P}}<0.001$ and ${ }^{* * \mathrm{P}}<0.005$

Table 5. Regression Path Coefficients $(\beta)$ Weights

\begin{tabular}{|c|c|c|c|c|c|c|c|}
\hline \multicolumn{3}{|c|}{ Hypothesis Path } & \multirow{2}{*}{$\begin{array}{c}\text { Estimate } \\
.168 \\
\end{array}$} & \multirow{2}{*}{$\begin{array}{l}\text { SE. } \\
.073 \\
\end{array}$} & \multirow{2}{*}{$\begin{array}{c}\text { CR. } \\
2.292 \\
\end{array}$} & \multirow{2}{*}{$\begin{array}{l}\text { P-value } \\
.021\end{array}$} & \multirow{2}{*}{$\begin{array}{l}\text { Results } \\
\text { satisfied }\end{array}$} \\
\hline BBW & $<---$ & PCS & & & & & \\
\hline H4- MLB & $<--$ & ATT & .139 & .061 & 2.276 & .011 & Satisfied \\
\hline H5- MLB & $<--$ & PSLU & .306 & .107 & 2.867 & .004 & Satisfied \\
\hline H6- MLB & $<--$ & PCS & .024 & .068 & .353 & .724 & Unsatisfied \\
\hline H8- MLB & $<--$ & BBW & .690 & .224 & 3.075 & .002 & Satisfied \\
\hline BI. & $<---$ & BBW & .074 & .045 & 1.636 & .102 & Satisfied \\
\hline H1- BI. & $<--$ & ATT & .020 & .056 & .364 & .716 & Unsatisfied \\
\hline H2- BI. & $<--$ & PSLU & .551 & .104 & 5.298 & $* * *$ & Satisfied \\
\hline H3- BI. & $<---$ & PCS & -.117 & .062 & -1.889 & .056 & Satisfied \\
\hline
\end{tabular}

Note: Sign ${ }^{* * *} \mathrm{P}<0.005,{ }^{* * \mathrm{P}}<0.001$ and ${ }^{*} \mathrm{P}<0.01$ respectively. $\mathrm{BBW}=$ broad bandwidth, $\mathrm{PCS}=$ perceived crowdsource, $\mathrm{ATT}=\mathrm{Attitude}, \mathrm{MBL}=$ mobile learning behavior, PSLU = perceived self-learner usefulness, $\mathrm{BI}=$ behavior intention performance

of Fit Index (AGFI), Comparative Fit Index (CFI), Tucker-Lewis Index (TLI), Normed Fit Index (NFI), and Chi-Square/ Degree of Freedom (Chsq/df) as hyphenated in Table 4 with their respective benchmarks (Awang, Afthanorhan, Mamat, \& Aimran, 2017). The fitness indexes verified from the study of multiple categories of model fit shown in Table 4 acceptable benchmarks. This research is evidence that all measurements have good fitness per the results of the pooled-output values (Lewis, 2017). We, therefore, conclude all the measurement and structural models are acceptable in this study to crowdsource technology communication mobile behavior.

\section{Hypotheses Tested Results}

The study has examined the path regression coefficients of standardized and unstandardized measurement model results of the hypotheses tested shown in Table 6. From Figure 2 displayed path coefficients structural model results indication from Table 5 of exogenously H4 Attitude to MLB ( $\beta=0.139, t=2.276, p<.011)$, H5 PSLU to MLB ( $\beta=0.306, t=2.867, p<.004)$ and H6 PCS to MLB ( $\beta=$ $0.024, \mathrm{t}=0.353, \mathrm{p}<.724$ ) apart from the latter $\mathrm{H} 4$ and $\mathrm{H} 5$ satisfied the causal effect of positive significant to mobile learning communication.
The result is a new dimensional twist of crowdsourcing technology ambient to individual-centered. Furthermore, H1 Attitude to Behavior intention $(\beta=0.020, t=0.364, \mathrm{p}<.716), \mathrm{H} 2$ perceived self-learner usefulness to behavior intention $(\beta=0.551, t=5.298, p<.000)$. Again, perceived crowdsource to behavior intention $(\beta=-0.117, \mathrm{t}=-1.889$, $\mathrm{p}$ $<.056$ ) are all remarkable $\mathrm{H} 1, \mathrm{H} 2$ and $\mathrm{H} 3$ satisfactorily positive and significant to behavior intention of using mobile communication technology in performing learning routines Hwang and $\mathrm{Fu}$ (2019), also accepting the current negative effect of crowdsourcing technology.

In the structural correlation indicators from Table 5, Figure 2, H9 Attitude to perceived self-learner usefulness shows a strong relationship of 0.70 . H10 perceived self-learner usefulness to perceived crowdsource is 0.79 whilst attitude to perceived crowdsource is 0.83 a correlation below the threshold of 0.85 . Therefore, the latent exogenous of Attitude, Perceived Self-Learner Usefulness and perceived Crowdsource (CS) relationships satisfied the discriminant validity test because they are below 0.85 (Awang et al., 2017). The value of the coefficient determinant of $\mathrm{R}^{2}=0.74$ thus $74 \%$ estimation power of endogenous behavior intention didactic with mobile technology innovation. 


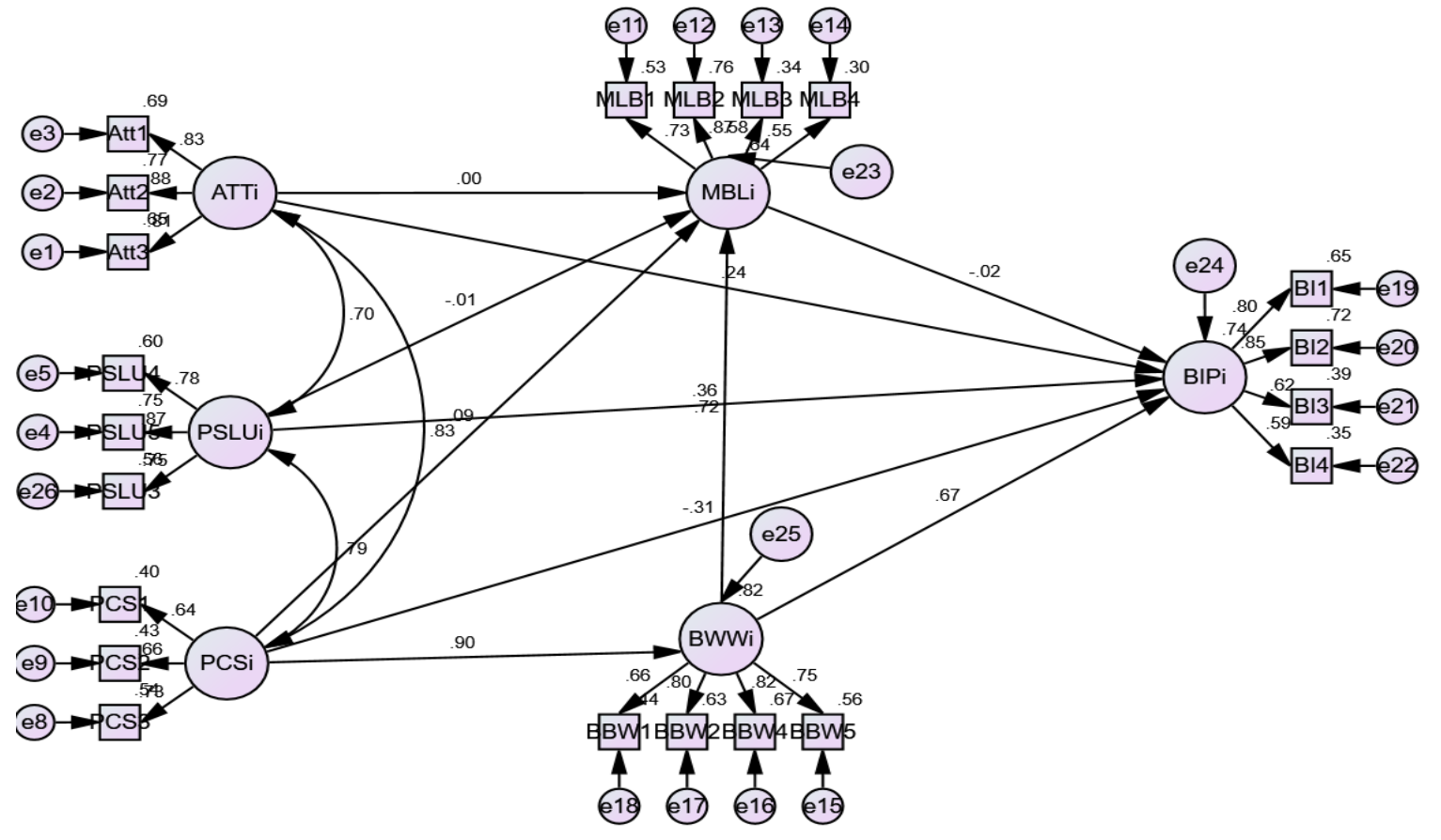

Figure 2. The Unstandardized Path Regression Path Coefficients for the Structural Model

Table 6. Correlations of the Covariance

\begin{tabular}{|c|c|c|c|c|c|c|c|}
\hline & Hypotheses & & Estimate & SE. & CR. & $\mathbf{P}$ & Label \\
\hline $\mathrm{H} 9=\mathrm{ATT}$ & $\langle--\rangle$ & PSLU & .336 & .042 & 8.038 & $* * *$ & satisfied \\
\hline $\mathrm{H} 10=\mathrm{PSLU}$ & $<-->$ & PCS & .348 & .042 & 8.391 & $* * * *$ & Satisfied \\
\hline $\mathrm{H} 11=\mathrm{ATT}$ & $<-->$ & PCS & .335 & .040 & 8.293 & $* * *$ & Satisfied \\
\hline
\end{tabular}

Note: ATT = Attitude, PSLU = perceived self-learner usefulness, PCS = perceived crowdsource, correlation is sign @ ${ }^{* * * P}<0.005$

Table 7. Mediation effects IV (ATT, PSLU, PCS) and DV (MLB) of the study

\begin{tabular}{ccccc}
\hline DV & Effect & $\boldsymbol{\beta}$ & t-values & p-values \\
\hline & 0.4052 & 0.486 & 8.3373 & 0.001 \\
\hline MBL 1 & 0.026 & 0.0135 & 0.0055 & 0.058 \\
\hline MBL2 & 0.0312 & 0.0162 & 0.0066 & 0.069 \\
\hline MBL3 & 0.0258 & 0.0133 & 0.0055 & 0.057 \\
\hline
\end{tabular}

Note: MBL1 = indirect effect of IV on DV, MBL2 = partially standardized effects on IV on DV, MBL3 = completely standardized effects IV on DV

The elaborative hypothesis of mobile learning behavior to behavior intention induced the model insignificantly $(\beta=0.010, t=1.636, p$ $<.851)$, therefore, complete mediation is achieved, broadband to mobile learning behavior is magnified significantly $(\beta=0.131, \mathrm{t}=2.818, \mathrm{p}$ $<.002$ ). The study objective for effective broadband has efficiently enhanced mobile learning behavior in a collective learning environment as well as self-learner usefulness for knowledge acquisition (Baek \& Touati, 2017; Yan et al., 2020). The moderation effect has proved a correlation of mobile learning on behavior intention from Table 5 .

The mediation effect Table 7, of mobile learning behaviors on behavior intention performance on Attitude, PSLU, and PCS using the PROCESS condition of path analysis regression performed (Hayes, 2017). Table 7 shows direct effect of $(\beta=.4052, t=8.3373, p=<0.001)$ which is positively significant. The indirect effect also shows significant results of $(\beta=0.0260, p=<0.005),(\beta=0.0312, p=<0.006)$ and the complete standardized shows significant results of $(\beta=0.0258, \mathrm{p}=<$ 0.005 ). The behavior intention of learners' prior performance of mobile effectiveness was regressively influenced by mobile learning behaviors of the technology Attitude, PSLU, and PCS. Impressively and by magnitude, all the exogenous variables were decreased and remained significant in the study. The study mediation is complete with MLB to $\operatorname{BIP}(\beta=0.0258, \mathrm{P}=<0.005)$, thereby, supporting H4, 5 and 6 in the study.

Figure 3a Perceived crowdsource (IV) to mobile learning behavior (DV) moderation (BBW) is a complete buffer interaction congruence to the digital content adoption by academics. The consistency though significance broadband on mobile learning, justification of the moderation effect on technology communication. However, the insignificant indirect effect of mobile learning on behavior intention from Appendix 2, unstandardized path regression reduction of correlation effect indication dampen the structural model of the mediation effect. Appendix 2 indication of unstandardized values of the regression path coefficient, showing the interaction effects of broadband causality on mobile learning behavior to perceived crowdsource. The output significantly shows exogenous broadband 


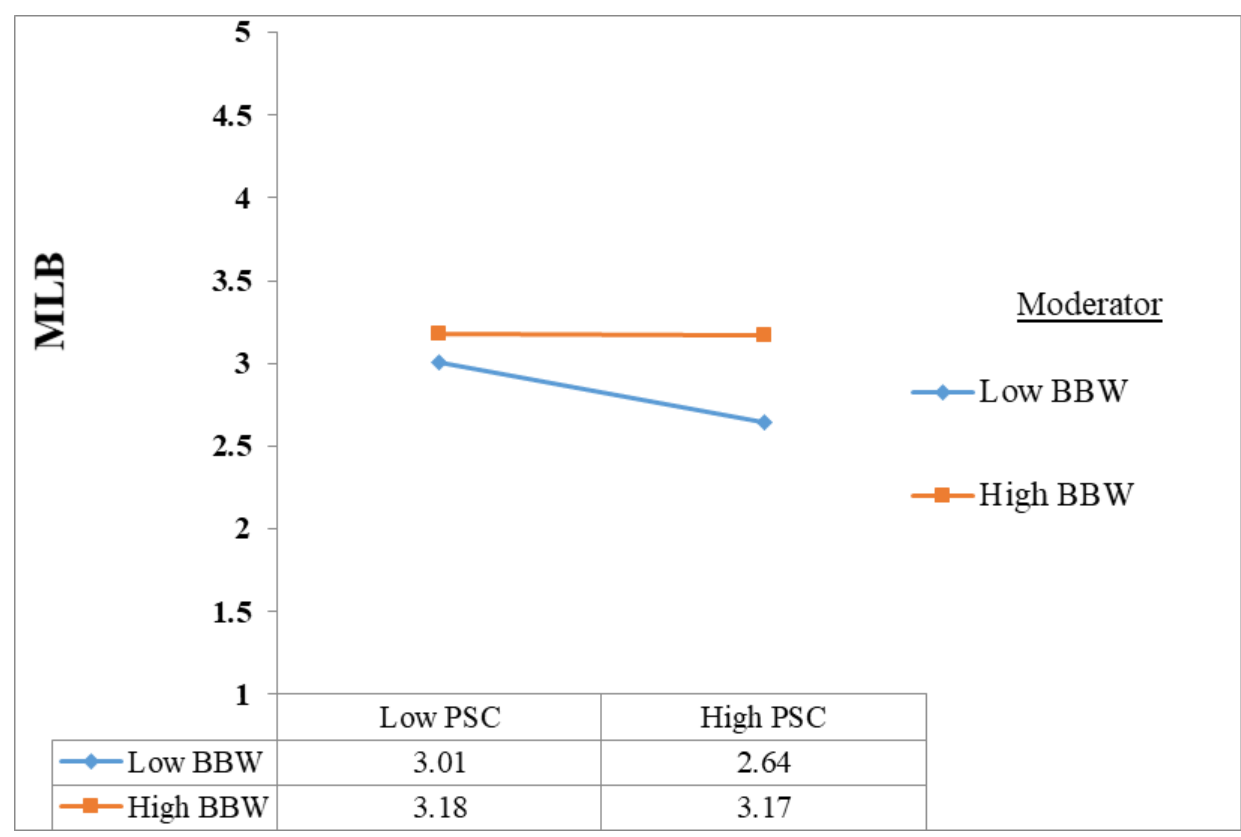

Figure 3a. Moderating effect of broadband (BBW), on the relationship of perceived crowdsource (PCS), and mobile learning behavior (MLB)

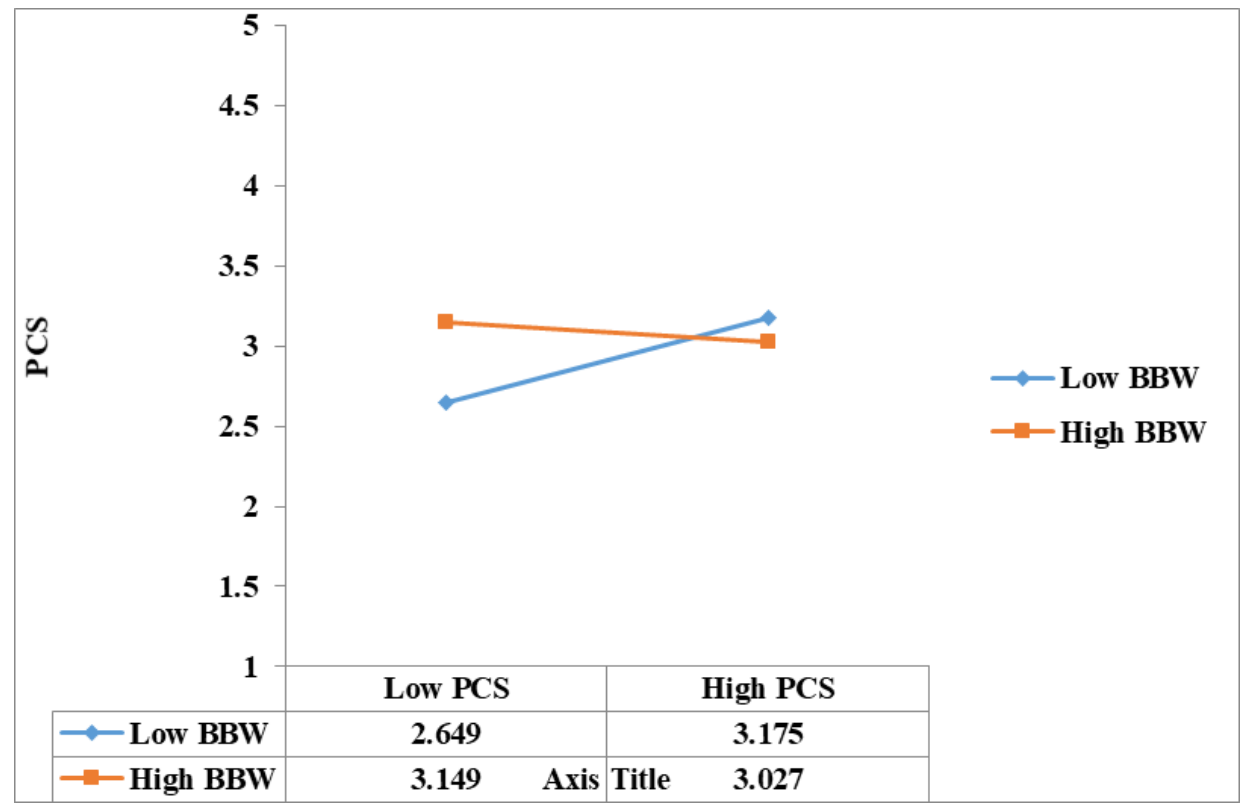

Figure 3b. Moderating Effect of broadband (BBW) on the relationship of perceived crowdsource (PCS) and behavior intention performance (BIP) Note: $\mathrm{BIP}=$ behavior intention performance, $\mathrm{PSC}=$ perceived crowdsource, $\mathrm{MLB}=$ mobile learning behavior, $\mathrm{BBW}=$ broad bandwidth .

(BBW) correlated effect to behavior intention $\beta=0.82$ and mobile learning $\beta=0.31$, the input significantly reaffirms the induced value of mobile learning behavior to behavior intention $\beta=-0.03$ in the context of crowdsourcing community.

\section{DISCUSSION AND CONCLUSION}

The study empirical findings are Bandura's Social Learning Theory (SLT) and TPB. The variance explained about $74 \%$ of the behavior intention of mobile learning intervention against the covariance. The heterogeneity of knowledge-seeking web-based setting, inured crowdsource community setting through the standardized path coefficient. Perceived crowdsource is consistent with perceived risk and subjective norms on cloud technology adoption (Ho, Ocasio-Velázquez,
$\&$ Booth, 2017). The findings have a paradoxical effect of perceived selflearner usefulness, and Attitude of learners' positively significant. However, perceived crowdsource negatively significant to behavior intention performance but, positively significant to mobile learning behavior. Ren et al. (2020) showed significant situational difference effects of communication WOC. The study magnitude effect of perceived crowdsource is significant to broadband in pursuance to learning. To the best of the author's knowledge, this is a first study crowd-community social learning determinant of individual or group. Mason and Watt (2012), allude that, interconnected learners can diffuse through crowd-community experience for a collective academic ride. Undoubtedly, students are intrinsic in social network crowd tasks for information sharing, community interactivity, collaborative, collective learning environment with convenience (Barber, King, \& Buchanan, 2015). Similarly, the study found that Attitude, PSLU, has a significant 
relationship with behavior intention on social learning. Our study clue came from the current teaching methodology adopted by the University of Science and Technology of China (USTC) mixed culture of international students for continuous semester lectures during the locked-down of COVID-19. The study contribution is a crowdcommunity of learners from diverse cultures sharing knowledge facilities by mobile self-centeredness. An effective internet broadband portal enhances mobile-learning constructively. The finding of mobile technology communication in an environment of effective wireless networks in China is consistent with (Mayer, 2020). However, is inconsistent with LEGO's (2014), organizational learning with crowdsourcing, IT-enabled coordination, and collaboration system core to the businesses. Therefore, the insignificance can be related to perceived crowdsource in the context of academia, as such does not affect behavior intention but affect mobile learning social influence.

In another development, gamified crowdsourced systems are scattered empirical pieces that need to be scholarly synthesized into a body of intellectual capacity. It is evident 'the crowds' potential in knowledge acquisition designed for educational 'problem-solving' is a technology novel phenomenon. In the same vein, mobile learning did not affect behavior intention, which is due to the mediation role, and users engaged technology more on social interactivity than performing learning outcomes. In the study of Abu-Al-Aish (2014), mobile learning and wireless networks are indisputable gained performance in the educational arena. Broadband causality of mobile learning is newly explored research interest, due to students' continuous use of online education. Consistent with blended and distance learning attitude (Bervell \& Umar, 2018; Falode, Chukwuemeka, Bello, \& Baderinwa, 2020). However, it is crystal clear the absence of effective broadband (BBW) renders mobile learning useless, therefore, expected to moderate mobile learning behavior, which eventual met the study expectation. Attitude to mobile learning appears hypothetically significant (weak) in the study; the majority of studies from professional scholars have proven consistent with Attitude on behavior intention ( Karimi, 2016).

In conclusion, learner's behaviors in knowledge sourcing within a crowd community network with mobile communication. Eventually, mobile communication has witness effective broadband to ensure selfcentered learning vis-à-vis crowdsource technology. This study has contributed to creating a web of crowd community-learners network. The study has also enhanced crowdsource technology in self-centeredlearning for collaborative performance in education through effective broadband in Pro-COVID-19. The crowd of learners often interconnected towards 'problem-solving' usual using mobile-learning. In the case of any effective knowledge communication, developmental faculty, and the ability to learn new. The broadband and mobilelearning moderation-mediation interactivity in the model is marvelous as hypothesized. Mobile dominance in recent times over computers is justifying the magnificence of community crowdsource technology. We have accurately evaluated the crowdsourced technology of mobile learning as an online facility in physical distancing situations, also due to unavailable one-learner-one-computer in societies. Therefore, instigates government policy of ensuring wider broadband for mobile learning behavior to achieving performance in communities. A potential networking group or individual solving intellectual, knowledge-connect as crowdsourced (Morschheuser, Hamari, Koivisto, \& Maedche, 2017). The initiative of crowdsourcing integrated with academic learning novel mobile learning is an open innovation IT- information processing with learning experience embedded with the knowledge sharing paradigm. As information begot knowledge, knowledge begot resource that serves future individual educational development.

\section{Limitations and Future Research}

We studied the premix of crowdsourcing technology in communication efforts to enhance the continuous use of mobile learning. This study sourced data from international students in China during the COVID-19 period, but, cannot account for underdeveloped technologies. The proposed model, though, represented trends of achieving self-regulated learning mechanisms, in crowd-based community mobility. Firstly, the study is based on social psychology with a convenient sampling technique, drawn sampling from one section; in the future, the sample can cut across developing regions. Secondly, future studies are intended to use philosophical theory from "Great Learning" from Confucius's analects assessment communitybased crowd learning in today's' education. "Great Learning” theory engaging learners' in a society cluster to study their network roles against performance indices in community-knowledge sourcing is paramount.

\section{REFERENCES}

Abu-Al-Aish, A. (2014). Toward mobile learning deployment in higher education (Doctoral Thesis). Brunel University, London. Retrieved from https://bura.brunel.ac.uk/bitstream/2438/7998/1/Fulltext Thesis.pdf

Ajzen, I., Netemeyer, R., \& Ryn, M. Van. (1991). The theory of planned behavior. Organizational Behavior and Human Decision Processes, 50(2), 179-211. https://doi.org/10.1016/j.drugalcdep.2011.10.011

Alenezi, A. M., \& Salem, M. A. (2017). Implementation of Smartphones, Tablets and their Applications in the Educational Process Management at Northern Border University. International Journal of Educational Sciences, 18(1-3), 56-64. https://doi.org/10.1080/09751122.2017.1335051

Allen, B. J., Chandrasekaran, D., \& Basuroy, S. (2018). Design Crowdsourcing: The Impact on New Product Performance of Sourcing Design Solutions from the "Crowd. American Marketing Association Journal of Marketing, 82(2), 106-123. https://doi.org/10.1509/jm.15.0481

Alqahtani, M., \& Mohammad, H. (2015). Mobile Applications' Impact on Student Performance and Satisfaction. Tojdel The Online Journal of Distance Education and E-Learning., 14(4), 102-112.

Awang, Z., Afthanorhan, A., Mamat, M., \& Aimran, N. (2017). Modeling Structural Model for Higher Order Constructs (HOC) Using Marketing Model. World Applied Sciences Journal, 35(8), 14341444. https://doi.org/10.5829/idosi.wasj.2017.1434.1444

Awang, Z., Afthanorhan, A., Mohamad, M., \& Asri, M. A. M. (2016). An evaluation of measurement model for medical tourism research: the confirmatory factor analysis approach. International Journal of Tourism Policy, 6(1), 29. https://doi.org/10.1504/ijtp.2015.075141

Ayvazo, S. (2015). Applied behavior analysis services in public schools in Israel: examining functional behavior assessment processes. European Journal of Behavior Analysis, 16(2), 338-350. https://doi.org/10.1080/15021149.2015.1108540 
Baek, Y., \& Touati, A. (2017). Exploring how individual traits influence enjoyment in a mobile learning game. Computers in Human Behavior, 69, 347-357. https://doi.org/10.1016/j.chb.2016.12.053

Bandura, A. (1991). Social cognitive theory of self-regulation. Organizational Behavior and Human Decision Processes, 50(2), 248-287. https://doi.org/10.1016/0749-5978(91)90022-L

Barber, W., King, S., \& Buchanan, S. (2015). Problem based learning and authentic assessment in digital pedagogy: Embracing the role of collaborative communities. Electronic Journal of E-Learning, 13(2), 59-67.

Beglar, D., \& Nemoto, T. (2014). Developing Likert-scale questionnaires. JALT2013 Conference Proceedings (pp. 1-8). Tokyo: JALT. Retrieved from https://jalt-publications.org/sites/default/ files/pdf-article/jalt2013_001.pdf

Bervell, B., \& Umar, I. N. (2018). Blended learning or face-to-face? Does Tutor anxiety prevent the adoption of Learning Management Systems for distance education in Ghana? Open Learning: The Journal of Open, Distance and e-Learning, 35(2), 159-177. https://doi.org/10.1080/02680513.2018.1548964

Bhattacherjee, A., Perols, J., \& Sanford, C. (2008). Information technology continuance: A theoretic extension and empirical test information technology continuance: A theoretic extension and empirical test. Journal of Computer Information Systems, 49(1), 17-26. https://doi.org/10.1080/08874417.2008.11645302

Çakar Mengü, S., \& Mengü, M. (2017). The importance of international distance learning for the development of intercultural communication. In Proceedings of 8h INTE ITICAM IDEC (vol. 3, pp. 726-745).

Campbell, M., Detres, M., \& Lucio, R. (2019). Can a digital whiteboard foster student engagement? Social Work Education, 38(6), 735-752. https://doi.org/10.1080/02615479.2018.1556631

Cortez, C. P. (2020). Blended, Distance, Electronic and VirtualLearning for the New Normal of Mathematics Education: A Senior High School Student's Perception. European Journal of Interactive Multimedia and Education, 1(1), e02001. https://doi.org/10.30935/ejimed/8276

Crittenden, W. F., Biel, I. K., \& Lovely, W. A. (2018). Embracing Digitalization: Student Learning and New Technologies. Journal of Marketing Education, 41(1), 5-14. https://doi.org/10.1177/ 0273475318820895

Cumiskey, K. M., \& Ling, R. (2015). The Social Psychology of Mobile Communication. In S. S. Sundar (Ed.), The Handbook of the Psychology of Communication Technology. https://doi.org/10.1002/ 9781118426456.ch10

Davis, F. D., Bagozzi, R. P., \& Warshaw, P. R. (1989). User acceptance of computer technology: a comparison of two theoretical models. Management Science, 35, 982-1003. https://doi.org/10.1287/ mnsc.35.8.982

Doargajudhur, M. S., \& Dell, P. (2018). The Effect of Bring Your Own Device (BYOD) Adoption on Work Performance and Motivation. Journal of Computer Information Systems, 60(6), 518-529. https://doi.org/10.1080/08874417.2018.1543001
Eze, K., N. O. Sadiku, M., \& M. Musa, S. (2018). 5G Wireless Technology: A Primer. International Journal of Scientific Engineering and Technology, 7(7), 62-64. https://doi.org/10.5958/22771581.2018.00015.3

Falode, O. C., Chukwuemeka, E. J., Bello, A., \& Baderinwa, T. (2020). Relationship between Flexibility of Learning, Support Services and Students' Attitude towards Distance Learning Programme in Nigeria. European Journal of Interactive Multimedia and Education, 1(1), e02003. https://doi.org/10.30935/ejimed/8320

Furr, R. M., \& Bacharach, V. R. (2014). Validity: Estimating and evaluating convergent and discriminat validity evidence. In Psychometrics: An introduction (pp. 61-77.

Gregori, E. B., Zhang, J., Galván-Fernández, C., \& Fernández-Navarro, F. de A. (2018). Learner support in MOOCs: Identifying variables linked to completion. Computers and Education, 122, 153-168. https://doi.org/10.1016/j.compedu.2018.03.014

Gün, A., Demir, Y., \& Pak, B. (2019). Urban design empowerment through ICT-based platforms in Europe. International Journal of Urban Sciences, 1-27. https://doi.org/10.1080/12265934.2019. 1604250

Hair, Joe F., Sarstedt, M., Hopkins, L., \& Kuppelwieser, V. G. (2014). Partial least squares structural equation modeling (PLS-SEM): An emerging tool in business research. European Business Review, 26(2), 106-121. https://doi.org/10.1108/EBR-10-2013-0128

Hair, Joseph F., Ringle, C. M., \& Sarstedt, M. (2013). Partial Least Squares Structural Equation Modeling: Rigorous Applications, Better Results and Higher Acceptance. Long Range Planning, 46(12), 1-12. https://doi.org/10.1016/j.1rp.2013.01.001

Halder, I., Halder, S., \& Guha, A. (2015). Educational Use of Mobile Phones by Undergraduate Students: An Indian Perspective. Online Journal of Communication and Media Technologies, 5(4), 64-76. https://doi.org/10.29333/ojcmt/2526

Hayes, A. F. (2017). Using SPSS: A Little Syntax Guide. Retrieved from http://afhayes.com/using-spss-a-little-syntax-guide.html

Ho, S. M., Ocasio-Velázquez, M., \& Booth, C. (2017). Trust or consequences? Causal effects of perceived risk and subjective norms on cloud technology adoption. Computers and Security, 70, 581-595. https://doi.org/10.1016/j.cose.2017.08.004

Hossain, S. F. A., Nurunnabi, M., Hussain, K., Saha, S. K., \& Wang, S. (2019). Effects of variety-seeking intention by mobile phone usage on university students' academic performance. Cogent Education, 6(1), 1574692. https://doi.org/10.1080/2331186X.2019.1574692

Hwang, G.-J., \& Fu, Q.-K. (2019). Trends in the research design and application of mobile language learning: a review of 2007-2016 publications in selected SSCI journals. Interactive Learning Environments, 27(4), 567-581. https://doi.org/10.1080/10494820. 2018.1486861

Ibrahim, W. (2018). Cloud computing implementation in libraries: A synergy for library services optimization. International Journal of Library and Information Science, 10(2), 17-27. https://doi.org/10.5897/IJLIS2016.0748

Rodríguez, A. I., Riazaa, B. G., \& Sánchez Gómez, M. C. (2017). Collaborative learning and mobile devices: An educational experience in Primary Education. Computers in Human Behavior, 72, 664-677. https://doi.org/10.1016/j.chb.2016.07.019 
iSALT Team. (2014). Theory of Planned Behavior. iSALT Resources: Theories, Concepts, and Measures. Paper 1. Retrieved from https://cornerstone.lib.mnsu.edu/cgi/viewcontent.cgi?article=100 0\&context=isalt_resources

Karimi, S. (2016). Do learners ' characteristics matter? An exploration of mobile-learning adoption in self-directed learning. Computers in Human Behavior, 63, 769-776. https://doi.org/10.1016/j.chb.2016. 06.014

Keenan, M., Presti, G., \& Dillenburger, K. (2019). Technology and behaviour analysis in higher education. European Journal of Behavior Analysis, 21(1), 26-54. https://doi.org/10.1080/15021149.2019. 1651569

Lewis, T. (2017). Fit Statistics commonly reported for CFA and SEM. Cornell Statistics Department, 8, 0-1.

Lin, C.-C., Lin, V., Liu, G.-Z., Kou, X., Kulikova, A., \& Lin, W. (2019). Mobile-assisted reading development: a review from the Activity Theory perspective. Computer Assisted Language Learning, 33(8), 833-864. https://doi.org/10.1080/09588221.2019.1594919

Lin, H., Wang, Y., Li, C., Shih, Y., \& Lin, S. (2016). The Measurement and Dimensionality of Mobile Learning Systems Success: Development and Validation. Journal of Educational Computing Research, 55(4), 449-470. https://doi.org/10.1177/ 0735633116671324

Mayer, R. E. (2020). Where is the learning in mobile technologies for learning? Contemporary Educational Psychology, 60(December 2019), 101824. https://doi.org/10.1016/j.cedpsych.2019.101824

Morschheuser, B., Hamari, J., Koivisto, J., \& Maedche, A. (2017). Gamified crowdsourcing: Conceptualization, literature review, and future agenda. International Journal of Human Computer Studies, 106, 26-43. https://doi.org/10.1016/j.ijhcs.2017.04.005

Pagani, C. (2014). Diversity and social cohesion. Intercultural Education, 25(4), 300-311. https://doi.org/10.1080/14675986.2014.926158

Paulin, D., \& Haythornthwaite, C. (2016). Crowdsourcing the curriculum: Redefining e-learning practices through peergenerated approaches. Information Society, 32(2), 130-142. https://doi.org/10.1080/01972243.2016.1130501

Peng, T., Liang, H., \& Zhu, J. J. H. (2019). Introducing computational social science for Asia- Pacific communication research. Asian Journal of Communication, 29(3), 205-216. https://doi.org/10.1080/01292986.2019.1602911

Petrovčič, A., Slavec, A., \& Dolničar, V. (2018). The Ten Shades of Silver: Segmentation of Older Adults in the Mobile Phone Market. International Journal of Human-Computer Interaction, 34(9), 845-860. https://doi.org/10.1080/10447318.2017.1399328

Riley, S., Brooks, J., Goodman, S., Cahill, S., Branney, P., Treharne, G. J., \& Sullivan, C. (2019). Celebrations amongst challenges: Considering the past, present and future of the qualitative methods in psychology section of the British Psychology Society. Qualitative Research in Psychology, 16(3), 464-482. https://doi.org/10.1080/ 14780887.2019.1605275

Sánchez-Prieto, J. C., Olmos-Migueláñez, S., \& García-Peñalvo, F. J. (2016). Informal tools in formal contexts: Development of a model to assess the acceptance of mobile technologies among teachers. Computers in Human Behavior, 55, 519-528. https://doi.org/10.1016/ j.chb.2015.07.002
Schultze, U., and D. E. L. (2002). Studying knowledge management in information sys- tems research: Discourses and theoretical assumptions. MIS Quarterly, 26(1), 213-242.

Schunk, D. H., \& DiBenedetto, M. K. (2020). Motivation and social cognitive theory. Contemporary Educational Psychology, 60(December 2019), 101832. https://doi.org/10.1016/j.cedpsych. 2019.101832

Seidel, V. P., Langner, B., \& Sims, J. (2017). Dominant communities and dominant designs: Community-based innovation in the context of the technology life cycle. Strategic Organization, 15(2), 220-241. https://doi.org/10.1177/1476127016653726

Sharma, P. K., \& Misra, R. K. (2017). Core Self Evaluations Scale: An Empirical Attestation among Software Professionals. Procedia Computer Science, 122, 79-85. https://doi.org/10.1016/j.procs. 2017.11.344

Sharples, M., Taylor, J., \& Vavoula, G. (2005). Towards a theory of mobile learning. Proceedings of MLearn 2005, (May 2014).

Sheng, M., \& Hartono, R. (2015). An exploratory study of knowledge creation and sharing in online community: a social capital perspective. Total Quality Management \& Business Excellence, 26(1-2), 93-107. https://doi.org/10.1080/14783363.2013.776769

Smirnov, N., Easterday, M. W., \& Gerber, E. M. (2018). Infrastructuring Distributed Studio Networks: A Case Study and Design Principles. Journal of the Learning Sciences, 27(4), 580-631. https://doi.org/10.1080/10508406.2017.1409119

Statista. (2019). Internet usage worldwide. Statista.

Su, W., Sui, D., \& Zhang, X. (2018). Satellite image analysis using crowdsourcing data for collaborative mapping: current and opportunities. International Journal of Digital Earth, 13(6), 645-660. https://doi.org/10.1080/17538947.2018.1556352

Swanlund, D., \& Schuurman, N. (2016). Mechanism Matters: Data Production for Geosurveillance. Annals of the American Association of Geographers, 106(5), 1063-1078. https://doi.org/10.1080/ 24694452.2016.1188680

Toyama, K. (2018). From needs to aspirations in information technology for development. Information Technology for Development, 24(1), 15-36. https://doi.org/10.1080/02681102.2017. 1310713

Van der Linden, W. J., Klein Entink, R. H., \& Fox, J.-P. (2010). IRT Parameter Estimation with Response Times as Collateral Information. Applied Psychological Measurements, 34(5), 327-347. https://doi.org/10.1177/0146621609349800

Venkatesh, V., Morris, M., Davis, G., \& Davis, F. (2003). Technology acceptance model - research. MIS Quarterly, 27(3), 425-478.

Wang, Q., Ding, G., \& Yu, S. (2019). Crowdsourcing mode-based learning activity flow approach to promote subject ontology generation and evolution in learning. Interactive Learning Environments, 27(7), 965-983. https://doi.org/10.1080/10494820. 2018.1509875

Yan, B., Jian, L., Ren, R., Fulk, J., Sidnam-Mauch, E., \& Monge, P. (2020). The Paradox of Interaction: Communication Network Centralization, Shared Task Experience, and the Wisdom of Crowds in Online Crowdsourcing Communities. Communication Research, May 2020. https://doi.org/10.1177/0093650220915033 
Yan, G. (2019). Simulation analysis of key technology optimization of $5 \mathrm{G}$ mobile communication network based on Internet of Things technology. International Journal OfDistributed Sensor, 15(6). https://doi.org/10.1177/1550147719851454

Yang, H. L., \& Lin, S. L. (2019). The reasons why elderly mobile users adopt ubiquitous mobile social service. Computers in Human Behavior, 93, 62-75. https://doi.org/10.1016/j.chb.2018.12.005
Yang, J. C., Lin, Y. L., \& Liu, Y.-C. (2017). Effects of locus of control on behavioral intention and learning performance of energy knowledge in game-based learning. Environmental Education Research, 23(6), 886-899. https://doi.org/10.1080/13504622.2016. 1214865

\section{APPENDIX 1: QUESTIONNAIRES}

\section{Overview study trend and questionnaires}

Objectively, seeks to investigate students/learners respond inured in the field of 'mobile juste milieu, science, and communication crowdsourced technology. The crowd based-community of learners explorative, behavioral mobile communication a conservative continuous mechanism in academia. The questionnaires inclusively survey instruments for universities during Covid-19. Achieving this, we use Perceived Crowdsource (PCS) moderated by Broadband Mediation Mobile learning behaviors in universities in China. The researchers found major crowd tasks were resolved via mobile systems. The responses are expressed using the 5 -point Likert scale, ranging from $1=$ "strong disagreed" to $5=$ "strong agreed" respectively.

\section{Demographics Measures}

1. Gender: M F

2. Your level of education?

3. JHS: SHS: bachelor: masters': Ph.D.: others

4. Age; $18-25$ 26-34 35-45

5. Do you use a smart mobile phone? Yes No

6. Do you often search the internet with phone data? Yes No

Constructs Measurements

Attitude (Ajzen, Netemeyer, \& Ryn, 1991; Schultze, U., 2002)

1. I intend to use mobile learning anytime and anywhere on campus for academics.

2. Using mobile learning eases my retention to the group task.

3. Using mobile learning motivates my learning capacity.

4. Mobile learning encourages my reading habit.

5. I am always with my mobile device for information.

6. I enjoy using mobile learning as I move around.

Perceived Self-learner Usefulness (PSLU) (Bhattacherjee, Perols, \& Sanford, 2008; Venkatesh, Morris, Davis, \& Davis, 2003)

7. Having access to my mobile improves my knowledge of sourcing.

8. Using a mobile is less difficult to search for information online.

9. It's easy using mobile to share the content of learning or documents to colleagues.

10. I effectively download learnable materials with a mobile device.

11. Using a mobile is less stressful for reading in a go.

Perceived Crowdsourcing (PCS) (Allen, Chandrasekaran, \& Basuroy, 2018; Ho, Ocasio-Velázquez, \& Booth, 2017)

12. Crowd-based learning is network informative.

13. Using mobile is easy to crowd solve problems in the network.

14. I prefer using mobile to connect with learners than a computer.

15. Community-based group discussions make learning effective via mobile.

16. Teacher-learner discussed via mobile group chatting.

17. Crowd internet content is easy to access for knowledge collaboration.

Mobile Learning Behavior (MLB) (Ibrahim, 2018; Lin, Wang, Li, Shih, \& Lin, 2016)

18. I always use a mobile device to record information and knowledge sourcing. 
19. I use mobile interactive to chat for learning outside class.

20. I use mobile information to share knowledge anytime.

21. Mobile network compliments my crowd-based task.

22. Using mobile chatroom for idea exchanges and collective learning.

23. Mobile learning motivates group tasks.

Internet Broadband system (BBW) (Lin et al., 2016; Yan, 2019)

24. Broadband fastens mobile internet surfing.

25. Mobile breakthrough $5 \mathrm{G}$ is easier than a computer.

26. Mobile service quality is higher and user-friendly.

27. Mobile data ensure Covid-19 distance learning.

28. The mobile system appeals to the user with effective broadband.

Behavior Intention Performance (BIP) (Ajzen et al., 1991; Bhattacherjee, Perols, \& Sanford, 2008)

29. I intend to mobile learning for crowdsourcing tasks.

30. In the future, I will continue to use a mobile device for knowledge assessment.

31. Moving around with access to mobile facilitates my learning at any time.

32. I will use mobile learning in solving my academic problems.

33. Mobile learning makes reading simple and easier anywhere.

34. I intend to link up with teachers and colleagues via a mobile smart tool.

\section{APPENDIX 2}

The Standardized Path Regression Path Coefficients for the Structural Model

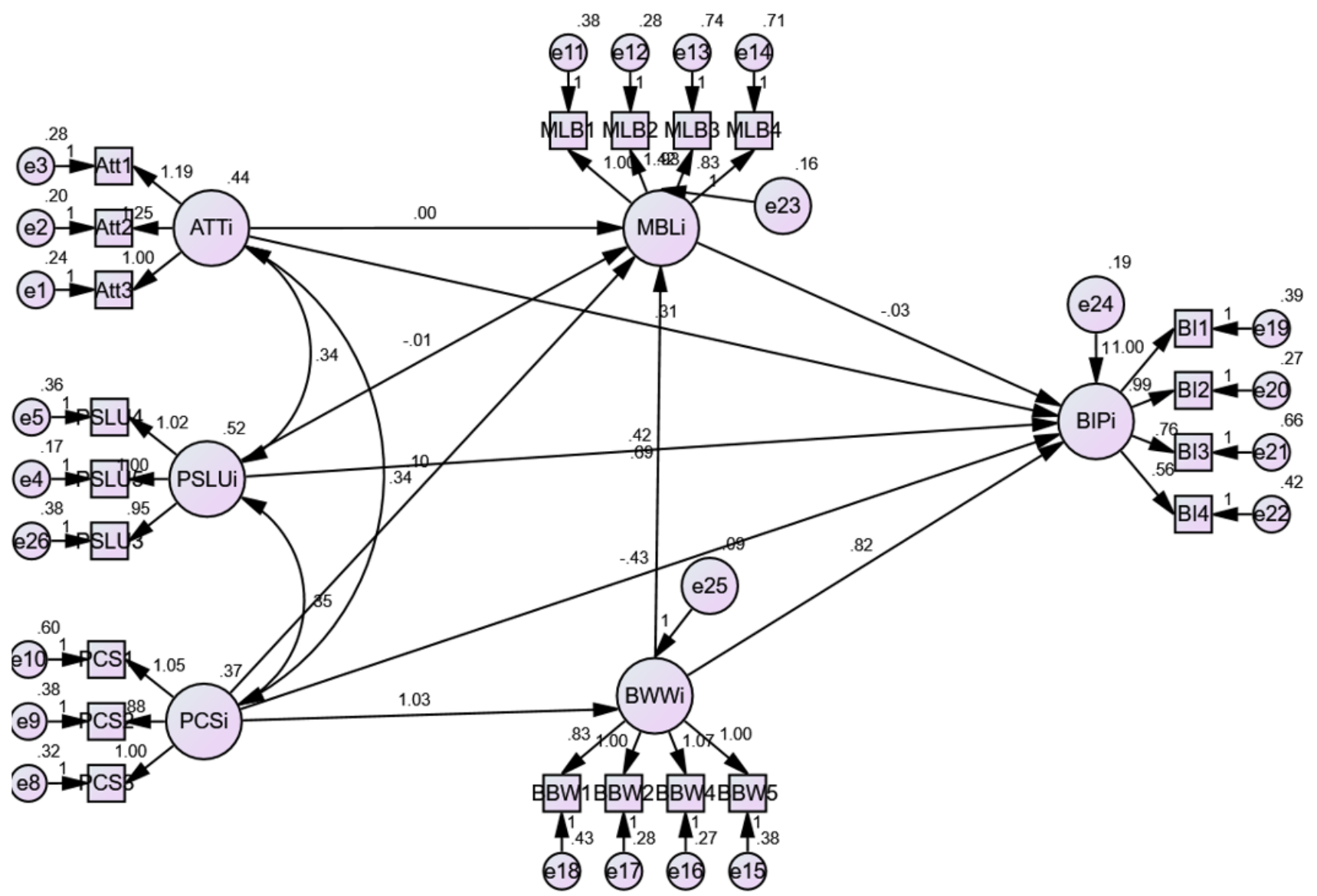

